\section{LA NINETTE DE MIGUEL MIHURA VUELVE AL CINE}

\author{
Juan A. Ríos Carratalá \\ Universidad de Alicante \\ JA.Rios@ua.es
}

\begin{abstract}
Ninette (2005), directed by José Luis Garci, is the second film adaptation of the comedy Ninette y un señor de Murcia (1964), written by Miguel Mihura. The article analises the criteria followed by the director and his habitual scriptwriter, Horacio Valcárcel, in their adaptation of the play, which is considered to be not very faithful to the original spirit of the play and in contradiction with the presentation of the film as an homage to Miguel Mihura.
\end{abstract}

KEY WORDS: Miguel Mihura; José Luis Garci; film adaptation; Ninette.

Miguel Mihura obtuvo uno de sus más importantes éxitos populares y de crítica con el estreno de la comedia Ninette y un señor de Murcia en septiembre de 1964, que fue galardonada con el Premio Nacional de Teatro Calderón de la Barca. Unos meses después y con la obra todavía en el madrileño Teatro de la Comedia, mientras otra compañía había iniciado una gira por provincias hasta completar las casi tres mil representaciones que proporcionaron beneficios millonarios al autor, Fernando Fernán-Gómez recibía el encargo de Tito's Films (Eduardo de la Fuente) para dirigir y protagonizar una adaptación cinematográfica con el mismo título cuyo guión escribiría en colaboración con José M. ${ }^{a}$ Otero. El triunfo popular se acrecentó tras el estreno simultáneo de la película en cinco cines madrileños (17-I-1966) y el comediógrafo aprovechó la circunstancia para escribir una continuación titulada Ninette, modas de París porque, según él, seguía enamorado de su protagonista.

La nueva comedia de Miguel Mihura volvió a contar con la aceptación del público cuando se presentó en el mismo teatro, justo dos años después de su primera parte. De acuerdo con las crónicas periodísticas, muchos espectadores repitieron porque estaban dispuestos a seguir sonriendo con aquella encantadora francesa hija de exiliados españoles que sedujo a un señor de Murcia, Andrés Martínez, un soltero de treinta y cinco años, propietario de

\section{MIGUEL MIHURA'S NINNETTE RETURNS TO CINEMA}

RESUMEN: Ninette (2005), de José Luis Garci, es la segunda adaptación cinematográfica de la exitosa comedia Ninette y un señor de Murcia (1964), de Miguel Mihura. El artículo analiza los criterios seguidos por el director y su guionista habitual, Horacio Valcárcel, en su adaptación, que se considera poco fiel al espíritu original de la obra teatral y contradictorio con la presentación de la película como homenaje a Miguel Mihura.

PALABRAS CLAVE: Miguel Mihura; José Luis Garci; adaptaciones cinematográficas; Ninette.

una librería especializada en catecismos y de vida amorosa poco intensa ${ }^{1}$. Ninette era una adorable, coqueta, caprichosa, imprevisible e irresistible joven que también sedujo al autor y los espectadores de la época porque, como dijo Antonio Díaz-Cañabate, "es una mujer inolvidable, es la mujer que uno hubiera querido tropezarse en la vida. Es la mujer que nos hace soñar" (Sáinz de Robles, 1968, 9). Un sueño reposado, sin estridencias y mantenido durante toda la comedia con la sonrisa de un escéptico, que como comediógrafo era partidario de una felicidad fruto de la acomodación ejemplificada por Andrés Martínez.

La popularidad de Ninette y un señor de Murcia propició varias reposiciones teatrales hasta la década de los setenta y, cuando parecía arrinconado el recuerdo de la francesita, el éxito se reavivó con una adaptación de ambas partes al formato de una serie televisiva dirigida por Gustavo Pérez Puig en 1984. Todavía estaba vigente el monopolio estatal en la televisión y los ocho capítulos protagonizados por Victoria Vera y Juanjo Menéndez cosecharon audiencias ahora inimaginables gracias, en buena medida, a un excelente reparto con figuras como Ismael Merlo, Florinda Chico y Alfredo Landa².

Ninette regresó a los escenarios en otras ocasiones, aunque $\sin$ las repercusiones de sus apariciones de la mano de Paula Martel, que alcanzó el rango de primera actriz 
tras dos temporadas en la piel de la adorable dependienta de las Galerías Lafayette. Su recuerdo perduró y en la temporada 2004-2005, cuando se preparaba el centenario del nacimiento de Miguel Mihura, Carmen Morales la paseó por buena parte de España hasta que pocos meses después, ya en el verano de 2005, José Luis Garci presentó su adaptación cinematográfica. Según sus palabras en la rueda de prensa, era un homenaje a un comediógrafo un tanto olvidado, del que "no se habla nada" a pesar de ser uno de los grandes maestros del teatro del siglo XX. A su lado, Elsa Pataky, la nueva Ninette, sonreía a las cámaras mientras lucía su espléndida belleza. Ninguno de los presentes en el acto habló de las casi tres mil representaciones y las giras por provincias tras el estreno de 1964, los más de doce millones de pesetas recaudados en el Teatro de la Comedia durante la temporada 1964-65, las audiencias millonarias y las reposiciones de la serie televisiva, la buena respuesta del público ante la primera adaptación cinematográfica, las reediciones del texto y otros datos de una trayectoria espectacular que se contrapone a cualquier noción del olvido. Si lo hubieran hecho, su película más que un homenaje al autor, habría aparecido como un intento de continuar un éxito que se prolongó durante dos décadas.

La adaptación de José Luis Garci fue elogiada en la prensa afín por Luis Herrero, Martín Prieto, Raúl del Pozo, Juan Manuel de Prada, Francisco Umbral y otros nombres tan previsibles como los de sus detractores, que son bastantes en los medios de comunicación del otro bando. El resultado en taquilla fue discreto, a pesar de una buena campaña de lanzamiento que aprovechó el hueco veraniego dejado por las producciones norteamericanas para adultos. Los sucesivos pases televisivos apenas han reavivado "un mito hecho carne" (Jordi Costa, El Mundo, 10-VIII-05), el de una Ninette que quedó en segundo plano ante el gancho mediático de Elsa Pataky.

El sugerente póster de la película, a imitación del popularizado por el perfume Opium de Yves Saint-Laurent, fue reproducido en multitud de ocasiones, pero nadie pareció pensar que su sensual y sofisticada protagonista era una virginal francesita de 1959 que tomaba cada día su "petit repas" de yogurt con jamón cocido ${ }^{3}$, escuchaba canciones de Jacques Brel, leía a Saint-Exupèry y trabajaba en las Galerías Lafayette. También quedó relegado el propio Miguel Mihura, el supuesto homenajeado con una adaptación cuyo análisis revela la libertad con que los guionis- tas manipularon sus textos. Los medios de comunicación recogieron las palabras de un José Luis Garci dispuesto a lanzar encendidos elogios al comediógrafo -"el primer acto de Maribel y la extraña familia es lo mejor que se ha escrito en el siglo XX" (El Mundo, 2005)-, se interesaron por la interpretación de una Elsa Pataky mil veces fotografiada en su debut como protagonista y poco más. Nadie preguntó acerca de las razones que habían Ilevado a los guionistas, José Luis Garci y Horacio Valcárcel, a trocear, alterar, mezclar, eliminar y refundir los textos de las dos comedias de Miguel Mihura, que sale malparado, incluso olvidado, en su supuesto homenaje. Los medios de comunicación, sobre todo en actos como las ruedas de prensa, se alimentan de lugares comunes a la búsqueda de un titular llamativo a pesar de haber sido mil veces leído. Aquellos periodistas, en el mejor de los casos, se quedarían satisfechos identificando lo eliminado con el consabido y fantasmal "lastre teatral", que se debe evitar en cualquier adaptación como si del pecado original se tratara.

La primera versión cinematográfica de Ninette y un señor de Murcia es una digna y divertida comedia. Su director, Fernando Fernán-Gómez, optó por una escrupulosa fidelidad al texto de Miguel Mihura (Ríos, 2003a), que se extendió a otros muchos aspectos del montaje teatral dirigido por el propio autor (reparto, vestuario, decoración, acotaciones escénicas...). Tanto es así que el habitualmente malhumorado y quisquilloso comediógrafo manifestó, en carta dirigida a una amiga hispanista, que la película de Fernando Fernán-Gómez "no es cine. Es teatro fotografiado" (Moreiro, 2004, 355). De haber sido otra la opción con el mismo director, la lamentación se habría centrado en la supuesta infidelidad a su texto, como ocurriera en Sólo para hombres (1960), una adaptación de Sublime decisión (1955) que analizo en el citado artículo. El comediógrafo era así de contradictorio e insatisfecho a tenor de los testimonios de quienes le conocieron.

Miguel Mihura estaba en la cumbre de un éxito que nunca reconoció como tal porque cultivaba un elegante victimismo en sus declaraciones públicas. Incluso dejaba correr rumores sobre su mala salud cuando la taquilla registraba cifras capaces de provocar la envidia universal. En esta ocasión, el creador de Ninette negociaba con la ventaja de ser un autor solicitado y había cobrado cuatrocientas mil pesetas por los derechos de adaptación de la comedia al "infierno del cine", que abandonó porque -según él- 
todos se sentían autorizados para opinar sobre su trabajo. Al parecer, la sustanciosa cantidad no fue un argumento suficiente para suavizar unas opiniones que siempre eran polémicas cuando sus obras las dirigían otros. La ponderación en esta materia no fue su principal virtud, tal vez por un exceso de celo y personalismo en el trabajo de dirección que también padecieron los intérpretes teatrales a sus órdenes.

No obstante, podemos entender el rechazo de Miguel Mihura en el sentido de que Fernando Fernán-Gómez se había limitado a poner la cámara para adaptar su comedia. No hubo tiempo para mucho más si tenemos en cuenta la cronología arriba indicada. El director, en colaboración con José M. ${ }^{a}$ Otero, sabía que una buena parte del éxito de Ninette y un señor de Murcia radicaba en unos diálogos perfectos y medidos con el objetivo de provocar la sonrisa del espectador. Apenas los perfiló para encajarlos en el montaje cinematográfico y no añadió una sola palabra. Tampoco alteró una construcción dramática cuya complejidad evidenciaba la madurez de un autor capaz de aparentar la sencillez siempre conveniente en la comedia. Mantuvo, asimismo, el atractivo perfil de unos personajes bien trazados hasta el punto de que resultan inolvidables. Y, por último, contó con un reparto adecuado donde todos eran conscientes de una responsabilidad que en los casos de Aurora Redondo, Rafael Somoza y Alfredo Landa ya habían asumido desde el estreno de la comedia. Fernando Fernán-Gómez y José M. ${ }^{a}$ Otero tenían estos mimbres a su disposición, sabían que no podían añadir nada de la misma calidad en una producción que culminó con las lógicas prisas para aprovechar el éxito teatral y se limitaron a aligerar algunas réplicas, añadir unas pocas imágenes de París rodadas en un par de días e inventarse otras que explicitaban las alucinaciones de Andrés Martínez, el señor de Murcia, fruto de su enclaustramiento en compañía de Ninette.

Muchos años después, Fernando Fernán-Gómez se arrepintió de estos últimos añadidos, verdaderamente pobres e innecesarios, pero fue tan poco lo que aportó al texto de la comedia original que en sus memorias, tal vez para compensar, imaginó que lo había modificado con el objetivo de suavizar la imagen satírica de los exiliados que aparecen en la obra de Miguel Mihura: "Cuando adapté al cine aquella comedia, me esforcé al escribir el guión en suavizar las aristas de la burla, aun en detrimento de la comicidad de la película, y Mihura estuvo totalmente de acuerdo en las correcciones" (1998, 553). No aporta pruebas ni entra en detalles.

Una comparación del texto del guión y el de la comedia nos indica que no se hizo nada en este sentido, salvo la eliminación de una anecdótica alusión a los presos en España (Mihura, 2004, 1212-3) y alguna frase suelta ${ }^{4}$. Estas leves modificaciones apenas afectan a una "burla" que fue motivo de polémica tras el estreno. Tampoco era imprescindible "suavizar las aristas", aunque el comediógrafo estuviera de acuerdo, tal y como manifiesta el adaptador tirando de una memoria capaz de tergiversar los hechos. En cualquier caso, la sátira política dirigida contra unos exiliados dispuestos a dar la vida tras decantarse entre "cocidistas y fabadistas" apenas conserva relieve. Comprendemos lo inoportuno de una presentación frívola o caprichosa que molestó a algunos críticos de izquierdas, pero Miguel Mihura no perdió los estribos en una materia política que apenas le interesó. Incluso conviene reconocer, a tenor de lo visto por entonces y algunos años después, que no siempre desenfocó el retrato de unos comportamientos cuyas contradicciones son resaltadas con una sonrisa atemperada por la ternura.

No obstante, lo importante es que la película de Fernando Fernán-Gómez, sea teatro filmado o no, todavía se puede ver con interés porque parte de un original excelente para provocar la agradecida sonrisa del espectador, lo respeta sabiendo donde están sus más destacados valores y los potencia mediante una sencilla puesta en escena basada en un trabajo de los intérpretes que, en buena medida, recoge los frutos de la dirección teatral del comediógrafo. Gracias a estos mimbres, todavía sonreímos cuando la vemos $y$, sobre todo, comprendemos las razones que provocaron el enorme éxito obtenido por Miguel Mihura.

El resultado es completamente distinto en el caso de la versión de José Luis Garci porque también fue diferente el proceso seguido y, sobre todo, la actitud con la que se afrontó la adaptación. El objetivo no era aprovechar el eco de un éxito teatral que todavía continuaba y apenas cabía alterar por su inmediatez, sino recuperar desde la nostalgia a Ninette, cuyo recuerdo parece haberse mezclado con el de otros modelos femeninos a modo de una tentación que puede vivir arriba, como la recreada por Billy Wilder, o dentro de la casa donde se aloja Andrés Martínez durante

ARBOR Vol. 187748 marzo-abril [2011] 317-324 ISSN: 0210-1963 
su frustrada visita a París. Desde esa subjetividad poco atenta al texto original, comprendemos algunas afirmaciones discutibles: "Ninette es Mihura hecho mujer" (EI Mundo, 2005). Se habría quedado sorprendido el comediógrafo "soltero, perezoso y sentimental", pues en más de una ocasión dijo que su teatro era él y una mujer

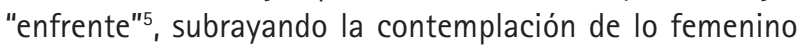
desde una admirada perspectiva en absoluto equiparable a la identificación.

La tajante opinión de José Luis Garci sobre la relación entre Ninette y el autor no es un error de apreciación, sino un intento más o menos consciente de justificar lo realizado en su pretendido homenaje a Miguel Mihura. Un homenaje al individuo y no a su "teatro", concepto que no recuerdo haber leído en las declaraciones con motivo de la presentación de la película. Desde esa perspectiva, los adaptadores se sienten libres a la hora de concebir una protagonista femenina que podria gustar al comediógrafo: "Elsa Pataki se acerca bastante a lo que pensaba Miguel Mihura sobre Ninette", afirma el director en la entrevista incluida en el DVD de la película. Esta discutible posibilidad no implica que el resultado se ajuste a lo plasmado en el texto de las comedias. La libertad de los guionistas con respecto al original conduce a que "el señor de Murcia" desaparezca del título, Ninette sea la protagonista absoluta del cartel de la película con una sofisticada y erótica imagen, la cámara se ponga a su servicio hasta el punto de prescindir de otros centros de interés y el lanzamiento publicitario descanse casi exclusivamente en la actriz Elsa Pataky. Estas decisiones son el fruto de una concepción global de la película y pueden resultar coherentes con un homenaje a Miguel Mihura, pero su teatro queda relegado a un segundo plano, a un mero punto de partida del que se toman elementos aislados, apuntes y una excusa argumental.

José Luis Garci y Horacio Valcárcel cuentan con una amplia experiencia en el campo de las adaptaciones, que de sus manos suelen salir con una impronta propia que caracteriza a buena parte de la filmografía de un director anclado en la nostalgia y que filma contra corriente, al margen de cualquier demanda relacionada con nuestro presente. En esta ocasión, optaron por adaptar conjuntamente Ninette y un señor de Murcia y Ninette, modas de París, añadir escenas y personajes de su cosecha, eliminar partes sustanciales de los textos teatrales, sintetizar al máximo los diálogos de las comedias hasta el punto de hacerlos irreconocibles mientras se inventan otros de cuestionable oportunidad $y_{\text {, }}$ sobre todo, confiar en el atractivo de Elsa Pataky de cara a la taquilla. Así, pues, se pasa de la literalidad de la versión dirigida por Fernando Fernán-Gómez a una libertad de discutibles resultados, pero que deja en un segundo lugar lo escrito por el autor homenajeado.

La decisión de utilizar la comedia original y su continuación ya la había adoptado Gustavo Pérez Puig en su serie televisiva, pero contaba con un formato más propicio para lo episódico y ocho capítulos de cuarenta minutos que le permitian dar cuenta del desarrollo de ambas comedias. Sin embargo, las andanzas de Ninette quedan reducidas al mero apunte en ocasiones y embutidas en la hora y media de la película de José Luis Garci. Se sacrifica así cualquier sutileza de la trama imaginada por Miguel Mihura, atento siempre a la dosificación de los detalles que caracterizan a los distintos personajes. Les conocemos, nos familiarizamos con ellos sin prisa alguna, sonreímos al escuchar sus ocurrencias salpicadas en unos diálogos que permiten el reposo gracias a una acción reducida al mínimo, les vemos construir una trama paradójica en la que Andrés Martínez se siente perplejo y desconcertado porque su aventura ha tomado un giro imprevisto... Este juego de ingenio seguido con un ritmo suave, que forma parte del atractivo teatral de Miguel Mihura, queda anulado por la necesidad de embutir en una película de metraje convencional dos comedias, siendo la segunda de un interés inferior y a pesar de que la original es autónoma con un final abierto cuya concreción en Murcia me parece prescindible. José Luis Garci manifestó en una entrevista televisiva que le daba miedo dirigir "una comedia encerrada en una caja de cerillas". Aludia así al desafío del trabajo en estudio con unos pocos decorados, pero optó por enclaustrar dos comedias en un espacio similar y en un tiempo que las ahoga. El resultado es un guión "inspirado en" que nunca pretende una traslación. La opción es correcta, frecuente y hasta oportuna a menudo, pero el problema radica en el interés de lo sacrificado y en el relativo atractivo de lo aportado como alternativa cinematográfica.

Los textos añadidos por José Luis Garci y Horacio Valcárcel se distinguen demasiado porque percibimos constantes de su filmografía y, conviene reconocerlo, resulta difícil estar a la altura de Miguel Mihura a la hora de dialogar y perfilar los personajes. Todavía más complejo me parece cultivar el humor cuando se insertan réplicas entre las del maestro 
de toda una generación que lo renovó. Ambos guionistas emprenden la tarea con desparpajo, pero sin aportar una presunta frescura que no se suele echar de menos cuando leemos las mejores comedias de Miguel Mihura. Puestos a comparar, considero más caducas y convencionales algunas de las réplicas añadidas, como la de madame Bernarda cuando anuncia que se marcha con su marido a ver una comedia de Marilyn Monroe seguida por un forum. Los guionistas aprovechan la ocasión para poner en boca de Ninette una alusión irónica a los debates cinéfilos de los años sesenta en torno a la comedia como evasión. Tal vez a un comediógrafo reacio al compromiso teatral como Miguel Mihura le hubiera hecho gracia este guiño en su momento, pero cuesta aceptar que hubiera incluido la oportunista réplica en unos textos que pocas veces admiten los recursos demasiado previsibles a la hora de buscar las fuentes del humor.

Lo eliminado en la adaptación de José Luis Garci y Horacio Valcárcel a veces resulta fundamental para comprender el desarrollo de una acción construida por Miguel Mihura como un mecanismo de relojería, donde pocas de las piezas desempeñan una función secundaria. Así, por ejemplo, en la película vemos al padre Roque (Miguel Rellán) en la casa murciana de Ninette sin que sepamos nada del porqué de su presencia. Su relación con Pedro, el peculiar exiliado convertido en triunfante jefe de taller tras su regreso a España, sigue un proceso de acomodación mutua que en la adaptación cinematográfica sólo cabe imaginarlo, con el consiguiente riesgo de que pase desapercibido para la mayoría de los espectadores. En un análisis más exhaustivo podríamos añadir otros ejemplos similares. No impiden el seguimiento del hilo argumental, pero dificultan la percepción de los centros de interés de unas comedias nada complejas, aunque sutiles y bien trenzadas.

La sintesis de los diálogos es obligatoria por la recreación de ambas comedias en un tiempo escaso, mucho menos de la mitad del que sería imprescindible para su puesta en escena teatral. También por las propias necesidades del medio cinematográfico, a pesar de que la filmografía de José Luis Garci nunca se haya caracterizado por lo comedido de la expresión verbal. No obstante, en Ninette dicha sintesis parte de una desconfianza a la hora de valorar la capacidad del espectador para degustar unos diálogos tan originales, escalonados y perfilados como los de Miguel Mihura. A menudo, los guionistas trocean y simplifican algunos de los momentos más recordados de las comedias, sobre todo por una virtualidad humorística que requiere un tiempo y un ritmo alterados en la adaptación cinematográfica. La fugacidad de la frase escogida, colocada como sintesis de un conjunto de réplicas escalonadas, tal vez sea aceptable en el lenguaje cinematográfico, pero relega la posibilidad de sonreír ante lo bien elaborado y madurado, con un tempo que admite la posibilidad de un espectador paciente y dispuesto por unos momentos a olvidarse de las frases sueltas con subrayado de carcajadas de tantas teleseries. El arte del diálogo "delicioso, gracioso e intencionado", según Alfredo Marquerie, es la piedra angular del ingenio teatral de Miguel Mihura, que también demostró su pericia en este aspecto como guionista y responsable de los diálogos de numerosas películas. José Luis Garci y Horacio Valcárcel habrán apreciado esta cualidad que todavía hoy distingue al comediógrafo de la mayoria de sus colegas contemporáneos, a menudo ineptos para calibrar las necesidades del cine en el tema del diálogo (Ríos, 2003b). El problema es que esa apreciación no se ha traducido en una mayor confianza depositada en los textos originales.

Y, por último, la relativa desvirtuación de las comedias de Miguel Mihura también se debe a la elección de una estreIla mediática como Elsa Pataky, cuyos rasgos de una belleza plenamente actual, que no se matizó para adecuarla a la de una joven de 1959, difieren en aspectos fundamentales de los de Paula Martel cuando se estrenaron las dos comedias, la mejicana Rosenda Monteros en el momento de la primera adaptación cinematográfica, Carmen Morales en el 2004 o, incluso, Victoria Vera, cuya belleza en 1984 respondía a una caracterización distinta y, sobre todo, con más pliegues para dar cuenta de un personaje abundante en recovecos y dobleces que se compaginan con una adorable sencillez. La presencia de Elsa Pataky en el reparto está de sobra justificada por la necesidad de promocionar la película en los medios de comunicación, pero dudo que fuera la actriz más adecuada para encarnar a una Ninette cuyo atractivo, tan sutil como efectivo, queda comprometido en manos de una mujer proclamada, también en el verano de 2005, como "la más deseada de España". Dos años después, según la revista $Q H$, ha sido elegida "la más sexy" por votación popular. Miguel Mihura pensó en una agradable sorpresa para el tímido Andrés Martínez, pero José Luis Garci le prepara un auténtico bombazo cuya desmesura rompe bastantes suturas de la comedia.

ARBOR Vol. 187748 marzo-abril [2011] 317-324 ISSN: 0210-1963 
El crítico cinematográfico Antonio Castro manifiesta en un blog que la Ninette de Elsa Pataky es "inteligente y manipuladora, cándida y atrevida, pero hay algo que no acabas de creerte nunca". Ese "algo" ya se percibe en el texto original. No obstante, la inteligencia teatral de Miguel Mihura orilla lo inverosímil de la situación central gracias al encantamiento de los espectadores, que caen rendidos ante las armas de la protagonista. Ésta debe reunir, además, unas concretas cualidades interpretativas y fisicas, en un punto intermedio entre la ingenuidad virginal indicada por el autor y la seducción de una Lolita de veintitrés años. En el caso de Elsa Pataky, el problema detectado por el crítico se acrecienta por la deslumbrante y fotogénica belleza de la actriz. Su imagen contrasta con la concepción original de un personaje que utiliza su encanto para trazar una tela de araña donde irremediablemente cae "el señor de Murcia". Ninette es hermosa, pero dispone de otras armas femeninas que nunca le serian necesarias a una mujer con un físico impactante, favorecido por un vestuario y un maquillaje en esa línea y subrayado con delectación por la cámara. Imaginarla virginal como hiciera Miguel Mihura ya rozaría la broma morbosa, añadida a una inverosimilitud en la que José Luis Garci cae por la comprensible necesidad de comercializar su película.

La interpretación de Elsa Pataky es correcta en todo momento y suponemos que ajustada a las directrices del director. Acierta con una sugerente dicción ya empleada por las actrices que la precedieron y crea su personaje con coherencia, aunque su limitada experiencia le lleva a un registro monocorde. Las protagonistas de las demás versiones, incluso la Rosenda Monteros que fue impuesta por los productores en detrimento de Paula Martel, juegan con un tira y afloja en su actitud ante el seducido Andrés Martínez. Cuentan con la imprescindible ayuda del texto de Miguel Mihura, siempre habilidoso a la hora de difuminar los contornos del "eterno femenino", pero en la adaptación de José Luis Garci dicho texto queda reducido al mínimo y pasa a un primer plano la seducción física, la de una imagen sin necesidad alguna de palabras. Muchos hombres la agradecemos porque se muestra con una generosidad digna de las comedias del destape, incluida la consabida ducha, pero nadie se la cree y, pasada la sorpresa de la consumación, se convierte en un motivo que roza los tantas veces encontrados en las descocadas películas que proliferaron durante la Transición.
José Luis Garci manifiesta en la entrevista incluida en el DVD de su película que Elsa Pataky "es una mujer con mucha hondura" y en El País la definió como "una mujer con luz interior" (9-VIII-2005). Se anticipa así a unas previsibles críticas cuya obviedad apenas merece un comentario ${ }^{7}$. No obstante, la interpretación monocorde de la protagonista, basada en una gestualidad fotogénica más propia de una modelo que de una actriz, contribuye al ritmo algo cansino de una "comedia romántica" -así la define el director- donde quedan difuminados muchos de los rasgos humoristicos. La raíz teatral de los mismos habría requerido otro tipo de interpretación, como la de Aurora Redondo, Rafael Somoza y Alfredo Landa en la versión de Fernando Fernán-Gómez. Beatriz Carvajal, Fernando Delgado y, sobre todo, Enrique Villén en el papel de Armando, "un hombre serio, que no se rie nunca", realizan un buen trabajo. Son profesionales solventes en los que José Luis Garci confía sin necesidad de casting alguno. Lamentamos que no permanezcan más tiempo en pantalla, que su labor sólo quede apuntada por una falta de protagonismo, alicorta por las muchas réplicas eliminadas y contagiada por un sentido de la nostalgia que se extiende al conjunto de la película en detrimento de la sonrisa con que fueron recibidas las comedias originales.

La película de José Luis Garci cuenta con el buen acabado propio de un equipo experimentado, conjuntado y brillante. La pegadiza música de Pablo Cervantes insufla ánimos y los decorados de Gil Parrondo justifican la opción de rodar toda la adaptación en un estudio. Algunos carteles del realismo socialista añaden explicitud y coherencia a una circunstancia política, la del exilio, que en la comedia acusaba la habitual subjetividad del autor. Son innecesarios, pero pasan desapercibidos. El problema es que buena parte del texto de Miguel Mihura también pasa desapercibido. Supongo que por una cuestión de desconfianza, de temor al fantasma de ese lugar común llamado "lastre teatral". A veces existe, como los fantasmas o las meigas, pero suele ser una coartada para una realización convencional, incapaz de utilizar la cámara al servicio de una teatralidad que puede dar buenos resultados en una pantalla. Así ocurrió en las exitosas versiones de Fernando Fernán-Gómez y Gustavo Pérez Puig. El riesgo habría sido superior cuarenta años después del estreno, con unos espectadores cada vez más alejados del lenguaje teatral $y$, por el contrario, acostumbrados a un humor televisivo cuya capacidad de contagio parece ilimitada. No obstante, si de homenajear a Miguel Mihura se trataba, considero que habría merecido la pena intentarlo, 
incluso con la colaboración de una Elsa Pataky que podria haber sido la virginal Ninette en el caso de haber matizado una imagen tan perfecta, seductora y rentable para aparecer con "unos libros, un yogur y un paquetito de fiambres". Se trataba de desconcertar y no de impactar al señor de Murcia. Tampoco es cierto que el texto original fuera una comedia romántica, sino de un humor cuyas paradojas y sorpresas apenas guardan relación con el amor.

Miguel Mihura, siempre escéptico y acomodaticio, termina Ninette, modas de París con la pareja protagonista hablando al público acerca de un futuro en Murcia: tiendas y negocios, niños, ahorros y, sobre todo, una Ninette que "se fue transformando en doña Alejandrina Sánchez de Martínez
Segura, una señora muy simpática, que a su marido le decía mon homme y que seguía escuchando discos de música francesa". José Luis Garci y Horacio Valcárcel finalizan su "comedia romántica" con una inventada escena en un lujoso hotel de Paris, donde de nuevo vemos al inefable personaje interpretado por Javivi reiterándose en sus gracias y una pareja dispuesta a pasar una glamorosa noche de amor. Elsa Pataky suelta su hermosa cabellera y se queda con una sugerente ropa interior de color negro. Ante semejante invitación, ningún espectador pudo pensar que, con el tiempo, se convertiría en doña Alejandrina Sánchez de Martínez Segura. Tal vez porque el negocio cinematográfico en España ya ni siquiera admite el escepticismo de un humorista cuyo homenaje queda pendiente de una mejor ocasión.

\section{NOTAS}

1 Así lo justifica el propio protagonista: "No porque yo tenga una marcada tendencia a la castidad, sino porque en Murcia, como en cualquier capital de provincia, siendo soltero, no se presentan demasiadas ocasiones de demostrar que se es hombre, a no ser que se líe uno a bofetadas con el camarero de un café... Como yo soy de derechas y vendo catecismos en la librería, no considero apropiado liarme a mamporros con mis clientes. Y como tampoco puedo hacer lo otro, estoy un poco incómodo en la vida $y_{1}$ según algunas virtuosas amigas de mi tía, estoy cargado de manías" (Mihura, 2004, 1189). Andrés decide, pues, escaparse a París para curarse las "manías".

2 Juanjo Menéndez y Alfredo Landa ya habian intervenido en el reparto original veinte años antes. Sus personajes, claro está, envejecen hasta el punto de modificar lo imaginado por Miguel Mihura. Pocas veces su obra ha contado con unos intérpretes de una edad adecuada y asi se ha perdido parte de su encanto.
3 Sobre la abundante, oportuna y graciosa utilización del francés en la obra, véase López Jiménez (2000).

4 En mi citado artículo me dejé llevar por la supuesta sinceridad de las palabras de Fernando Fernán-Gómez y cometí el consiguiente error. Nunca terminamos de comprender que las memorias de los actores suelen lindar el ámbito de la ficción. Véase Ríos (2001).

5 "Las mujeres, sí, son tema predilecto en mí. Yo, aunque no sé una palabra de mi obra, he dicho alguna vez que mi teatro soy yo y una mujer enfrente" (Mihura, 2004, 1507). Sobre esta actitud aplicada a la obra que nos ocupa, véase Serrano (2006).

6 Tanto Rosenda Monteros como Elsa Pataky tenían veintinueve años cuando interpretaron el papel, pero la primera los rejuveneció mediante el vestuario y el maquillaje, mientras que la segunda los reafirmó en su deseo, supongo que compartido por los responsables de la película, de reafirmarse en su imagen al margen de lo demandado por el papel.

7 Un ejemplo es el comentario de Carlos Boyero localizado en un chat
Aceptado: 14 de marzo de 2009 
de El Mundo: "Ver las rotundas tetas y el muy apreciable culo de esa sugerente señora no me compensa de tener que sufrir el inconfundible universo de Garci. Lo hice por estricta obligación profesional, pero su película me parece apestosa, como siempre".

\section{BIBLIOGRAFÍA}

Fernán-Gómez, Fernando (1998): El tiempo amarillo. Memorias ampliadas (19211997), Madrid, Debate.
Lara, Fernando y Eduardo Rodríguez (1990): Miguel Mihura en el infierno del cine, Valladolid, Seminci.

López Jiménez, Luis (2000): "El francés en Ninette y un señor de Murcia, de Mihura", Homenaje a Martínez Cachero, III, Oviedo, Universidad de Oviedo.

Mihura, Miguel (2004): Teatro completo, ed. Arturo Ramoneda, Madrid, Cátedra.

Moreiro, Julián (2004): Mihura. Humor y melancolía, Madrid, Algaba.

Ríos Carratalá, Juan A. (2001): Cómicos ante el espejo, Alicante, Universidad de Alicante.
- (2003a): "Fernando Fernán-Gómez, adaptador de Miguel Mihura", Studi Ispanici, n. 17, pp. 181-190. Edición digital en cervantesvirtual.com.

- (2003b): Dramaturgos en el cine español, 1939-1975, Alicante, Universidad de Alicante.

Sainz de Robles, Federico C. (ed.) (1966): Teatro español, 1964-1965, Madrid, Aguilar.

- (1968): Teatro español, 1966-1967, Madrid, Aguilar.

Serrano, Virtudes (2006): "Miguel Mihura y Ninette enfrente", Cuadernos del Lazarillo, n. ${ }^{\circ} 30$, pp. 43-49. 